\title{
POPULAR TREATMENT MODALITIES IN THE MANAGEMENT OF SACROILIAC JOINT DYSFUNCTION
}

\begin{abstract}
The treatment of sacroiliac joint (SIJ) dysfunction presents a clinical challenge for physiotherapists. The aim of this study was to investigate current physiotherapy practise in the management of acute and chronic SIJ dysfunction. A chart audit of 677 SIJ patient reports $(N=677)$ from 75 different private physiotherapy practises were analysed to determine the following: (1) the prevalence of the use of exercise therapy, and the types of exercise used in the management of SIJ dysfunction, and (2) the prevalence of other therapeutic modalities utilised alongside exercise therapy. The results of the study indicated that

Watson ED (M Sport Sc) ${ }^{1}$

Centre for Exercise Science and Sports Medicine,

School of Therapeutic Sciences, Faculty of Health Sciences, University of the Witwatersrand.

use of exercise therapy, specifically stretches and mobility exercises, is a popular treatment choice by physiotherapists. Joint mobilisations and soft tissue massage often accompanied exercise. Despite research outcomes suggesting both a strengthening and stabilisation program for the lumbo-pelvic complex, these approaches were less favoured.
\end{abstract}

KEY WORDS: SACROILIAC JOINT; EXERCISE THERAPY; MANAGEMENT; JOINT MOBILISATIONS.

\section{INTRODUCTION}

The sacroiliac joint (SIJ) is widely considered as a potential source of low back pain (Laslett, 2008; Forst et al., 2006; Cappaert, 2000; Schwarzer et al., 1995). Evidence suggests a SIJ dysfunction prevalence variation between 10 and $47.9 \%$ in the general population (Rupert et al., 2009; Laslett, 2008; Hancock et al., 2007; Hansen et al., 2007; Foley \& Buschbacher, 2006; Cohen, 2005; Dreyfuss et al., 2004; Toussaint et al., 1999). Studies have shown that in $13 \%$ of patients with persistent low back pain the SIJ has been confirmed as the origin of pain (Laslett, 2008; Hancock et al., 2007).

The assessment, treatment and management of SIJ dysfunction present a challenge for clinicians. Suitable evidence is lacking for the unequivocal support of one therapy over another. Current literature suggests the use of advice, manipulation and mobilisation, medication, bracing, radiofrequency denervation, advice and exercise. Medication (Vleeming et al., 2008; Foley \& Buschbacher, 2007; Forst et al., 2006), injections (Szadek et al., 2009; Rupert et al., 2009; Laslett, 2008; Foley \& Buschbacher, 2006; Cohen, 2005) and radiofrequency denervation
(Rupert et al., 2009: Hansen et al., 2007; Forst et al., 2006) are suggested for SIJ pain. Manipulation and mobilization techniques are readily considered among manual therapists to improve SIJ function (Vanelderen et al., 2010; Foley \& Buschbacher, 2007; Cohen, 2005; Liebenson, 2005; Sizer et. al., 2002; Lewit \& Rosina, 1999), however, few modalities are supported by strong high quality evidence (Fryer et al., 2009; Liebenson, 2004).

Acupuncture may provide pain relief, but there is currently not enough evidence in the literature to support this statement (Vleeming et al., 2008). There is also little evidence to support the use of passive treatments such as rest, massage and pelvic belts (Mitchell \& Esler, 2009; Vleeming et al., 2008; Laslett, 2008; Vleeming et al., 2008; Cohen, 2005;). Education and provision of information remain strongly recommended therapeutic agents for SIJ dysfunction (O'Sullivan, 2004). Postural (Liebenson, 2004) and lifting (Mitchell \& Esler, 2009) advice and modifications should be discussed with all patients. An active participation by the patient in their recovery must be continually emphasised (Horton \& Franz, 2007).

Exercise therapy, on the other hand, is well supported by the evidence (Laslett, 2008; Vleeming et al., 2008; Liebenson, 2004), especially those aimed at stabilizing the lumbo-pelvic unit when load transfer failure has been diagnosed (Cusi, 2010; Mitchell \& Esler, 2009; Chaitow, 2007; Forst et al., 2006), strengthening of the stabilising musculature (Pel et al., 2008; Liebenson, 2004; O"Sullivan, 2005; Liebenson, 2004; Hungerford et al., 2003; Franke, 2003; Van Wingerden et al., 2003; Richardson et al., 2002; Sizer et al., 2002; Snijdersad et al., 1998) and addressing functional patterns (Liebenson, 2004). SIJ dysfunction is addressed by a wide variation of therapies. The aim of this study was to assess the treatment interventions most commonly used by physiotherapists, with an emphasis on exercise therapy, in the management of SIJ dysfunction.
Correspondence Author:
Estelle D Watson
Centre for Exercise Science
and Sports Medicine,
Wits Medical School,
Wits, 2050,
South Africa
Email: estelle.watson@wits.ac.za 


\section{METHODS}

\section{Setting}

A retrospective chart audit was conducted from discharge reports submitted to a private health care company. A total of 75 physiotherapy practises were asked to submit discharge reports for all SIJ patient referrals. The physiotherapists submitted an initial and discharge report for all patients referred from the healthcare company. The physiotherapists received the report templates at referral. Reports submitted between the periods of January 2008 to July 2010 were gathered and assessed for the relevant data. All practises provided written consent to use the information provided in the report for research purposes.

\section{Patients}

A total of 677 reports were audited. Inclusion criteria consisted of all discharge reports with the terms 'sacroiliac joint' or 'SIJ' in the diagnosis section of the report. Exclusion criteria consisted of (1) cases where SIJ was not the provisional diagnosis provided by the clinician; (2) cases inclusive of secondary upper/ lower limb injuries; and (3) cases that were still undergoing treatment. The discharge report was designed by the researcher to assess the usage of each treatment modality. Physiotherapists selected all modalities that were used in treatment from a list provided. From an exercise therapy perspective, all therapists were provided with the options of stretches, mobility, strengthening, core stability, postural modifications, functional rehabilitation, proprioception, work focused rehabilitation, stability training, cardiovascular exercise, gait training and isokinetics. Various other therapeutic options were available for selection by the clinicians, and were assessed alongside the exercise therapy component. Definitions were not provided for each selection option. Clinician's selected the various options at their own discretion.

\section{Data Analysis}

Descriptive statistics were used to describe the prevalence of various treatment interventions. The cases were further divided into acute SIJ ( $\mathrm{n}=273$ ) and chronic SIJ $(n=404)$. Acute was defined, for the purpose of this study, as symptoms lasting no longer than 4 weeks, and chronic as persistence of symptoms for more than 4 weeks at the initial assessment (Bogduk \& McGuirk, 2002).

\section{RESULTS}

\section{Manual therapy}

The prevalence of both manual therapy and exercise interventions are illustrated in Figure 1. The most popular modality in the treatment of both acute and chronic SIJ dysfunction was joint mobilisations (used in $69 \%$ and $78 \%$ of cases, respectively). Soft tissue massage was also a popular choice, used in $52 \%$ and $55 \%$ of acute and chronic cases respectively. Ultrasound and IFT were also used in $43 \%$ of acute and $45 \%$ of chronic cases. Other modalities such as heat/ice, muscle energy techniques, myofascial release and acupuncture were all used in less that $30 \%$ of cases. The average number of modalities during one treatment series received per patient was 7.5.

\section{Exercise therapy}

The results for exercise modalities are shown in Table 1, as percentage for usage in each category. The three most popular forms of exercise therapy included stretches, mobility (range of movement exercises) and strengthening exercises. All three were seen to be more popular in the chronic phase of the injury, with stretches used in $74 \%$ of cases, mobility in $63 \%$ and strengthening in $62 \%$ of all cases. In the acute phase, these choices were slightly less favoured, with stretches being used in $68 \%$, mobility in $54 \%$, and strengthening in $52 \%$ of all cases. Other common choices included core stability (used in $48 \%$ of chronic, and $45 \%$ of acute cases) and postural/work modifications (used in 32\% of chronic, and 34\% of acute patients).

\section{Reason for discharge}

The selected 'reason for discharge' on the report was also analysed. The options on the report and responses are shown in Table 2. The majority of acute patients $(82 \%)$, and $80 \%$ of chronic patients completed treatment and were able to self manage at discharge from care. Non-compliance with treatment (two or more consecutive appointments not attended) appeared to be marginally higher in acute (7\%) versus chronic (6\%) patients. The need for further diagnostic investigation appeared to be higher in chronic SIJ patients compared to acute patients ( $5 \%$ and $3 \%$, respectively). Only $1 \%$ of acute patients were reported to have had a poor response to treatment.

\section{DISCUSSION}

Guidelines on recommended treatment approaches for SIJ dysfunction are few and good quality research is sparse. Liebenson (2004) proposes the key therapy components as advice about

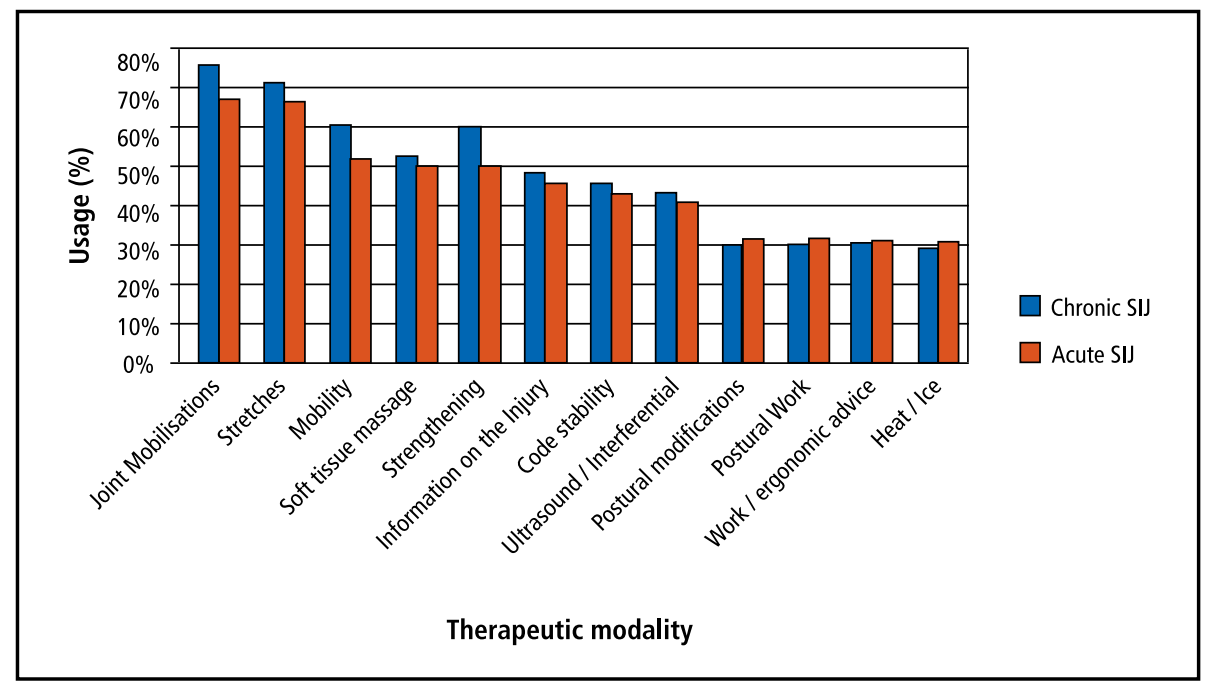

Figure 1: Popular physical therapy modalities in the treatment of SIJ dysfunction 
posture and support, manipulation of the SI joints alongside other manual therapies, and exercise of the stabiliser muscles. Dar et al. (2006) reported the use of mobilisations, manipulations, traction, compression and gliding in the treatment of SIJ dysfunction. The results of this study suggest that joint mobilisation is still the most preferred treatment option used in private practice in the management of SIJ dysfunction.

Exercise therapy has been advocated as the conservative therapy with the most potential for success (Laslett, 2008). The most commonly used exercise therapy was stretches followed by mobility exercises. Despite much evidence to suggest both a strengthening and a stabilisation program for the lumbopelvic complex (Mitchell \& Esler, 2009; Laslett, 2008; O'Sullivan \& Beales, 2007; Liebenson, 2004; Franke, 2003) these approaches were less favoured than expected, with the latter being used in less than half of all cases.

This study found that the use of soft

Table 1: A comparison of the choice of exercise therapies in the management of acute and chronic SIJ dysfunction

\begin{tabular}{|l|l|l|}
\hline Treatment modality & Chronic SIJ (n=404) & Acute SIJ (n=273) \\
\hline Stretches & $74 \%$ & $68 \%$ \\
\hline Mobility & $63 \%$ & $54 \%$ \\
\hline Strengthening & $62 \%$ & $52 \%$ \\
\hline Core stability & $48 \%$ & $45 \%$ \\
\hline Postural modifications & $32 \%$ & $34 \%$ \\
\hline Postural Work & $32 \%$ & $34 \%$ \\
\hline Functional rehabilitation & $16 \%$ & $14 \%$ \\
\hline Work-focused rehabilitation & $10 \%$ & $13 \%$ \\
\hline Proprioception & $12 \%$ & $11 \%$ \\
\hline Cardiovascular exercise & $1 \%$ & $1 \%$ \\
\hline Gait training & $1 \%$ & $2 \%$ \\
\hline Isokinetics & $0 \%$ & $0 \%$ \\
\hline
\end{tabular}

Table 2: Response to treatment based on clinician selected 'reason for discharge'

\begin{tabular}{|l|l|l|}
\hline Reason for Discharge & Chronic SIJ \% (N=404) & Acute SIJ (N=273) \\
\hline $\begin{array}{l}\text { Treatment complete/ } \\
\text { self help sufficient }\end{array}$ & $80 \%$ & $82 \%$ \\
\hline Non-compliance & $6 \%$ & $7 \%$ \\
\hline Further investigation required & $5 \%$ & $3 \%$ \\
\hline Other & $3 \%$ & $2 \%$ \\
\hline $\begin{array}{l}\text { Patient did not wish to continue } \\
\text { with treatment }\end{array}$ & $3 \%$ & $1 \%$ \\
\hline Patient receiving treatment elsewhere & $1 \%$ & $1 \%$ \\
\hline Recommendations not approved & $1 \%$ & $1 \%$ \\
\hline Alternative treatment recommended & $1 \%$ & $1 \%$ \\
\hline Poor response to treatment & $0 \%$ & $1 \%$ \\
\hline
\end{tabular}

tissue massage is a popular treatment choice. Other passive modalities were not used as frequently, possibly due to warnings of clinical dependence and ineffectiveness for SIJ dysfunction (Harman et al., 2009; Horton \& Franz, 2007; Poitras et al., 2005). There is no strong evidence for the use of myofascial techniques, muscle energy techniques and acupuncture (Vleeming et al., 2008) and physiotherapists chose these interventions in less than $30 \%$ of cases.

Liebensen (2004) recommends offering advice on lumbopelvic posture, and O'Sullivan (2004) strongly recommends provision of information on the injury (O'Sullivan \& Beales, 2007). It is interesting to note that education regarding the injury was provided in less than half of all cases, despite its clinical importance in aiding in patient compliance and recovery. Information was provided in $48 \%$ of acute and $51 \%$ of chronic SIJ patients. The effect of providing information on the outcome in these patients is worth further investigation (Vleeming et al., 2008).

The purpose of this study was to provide a general overview of current management of SIJ dysfunction in private physiotherapy practise. The certainty of the diagnostic accuracy for these patients should be interpreting with caution. Guidelines recommending various batteries of tests (Cusi, 2010; Fryer et al., 2009; Vleeming et al., 2008; Szadek et al., 2008; Foley \& Buschbacher, 2007; Cohen, 2005; Lurie, 2005) are available. Further research should compare current practise against such recommendations. Furthermore, research should address the specificity of the exercises provided, and the relationship between these exercises and outcome measures should be investigated.

\section{SUMMARY}

Treatment of SIJ dysfunction should be aimed at correcting underlying pathology, and alleviating symptoms and rehabilitation of stability of the pelvis (Cohen, 2005). Evidence supporting any one therapy is lacking, and it is of interest to assess what modalities physiotherapists are currently using in the management of this condition. 
The use of joint mobilisations and soft tissue massage are common and widespread amongst physiotherapists in the treatment of SIJ dysfunction. Exercise therapy is used frequently, and this is congruent with current recommendations. Common exercise therapy techniques include stretches, mobility and strengthening. There still remains a need in clinical practise to emphasise an educational approach, providing information to patients. This study highlights the need for well conducted, randomised controlled studies into the clinical and cost-effectiveness of the different therapeutic approaches to SIJ dysfunction, in order to provide clinicians with useful guidance to best practice.

\section{ACKNOWLEDGEMENTS}

The author would like to acknowledge the private healthcare company for the use of their data and resources, as well as all the physiotherapists and patients that participated, directly and indirectly in the completion of this study.

\section{REFERENCES}

Bogduk N, Mcguirk B 1970 Medical management of acute and chronic low back pain: an evidence-based approach. Elsevier, Amsterdam.

Cappaert TA 2000 The sacroiliac joint as a factor in low back pain: a review. Journal of Sport Rehabilitation 9:169-183.

Chaitow L 2007 Chronic Pelvic Pain: Pelvic Floor Problems, Sacro-Iliac Dysfunction and The Trigger Point Connection. Journal Of Bodywork And Movement Therapies 11: 327-339

Cohen SP 2005 Sacroiliac Joint Pain: A Comprehensive Review of Anatomy, Diagnosis and Treatment. Anesthesia \& Analgesia 101:14401453.

Cusi MF 2010 Paradigm for assessment and treatment of SIJ mechanical dysfunction. Journal of bodywork and movement therapies Doi: 10.1016/ j.jbmt.2009.12.004.

Dar G, Khamis S, Peleg S, Masharawi Y, Steinberg N, Peled N, Latimer B, Hershkovitz I 2008 Sacroiliac joint fusion and the implicatiosn for manual therapy diagnosis and treatment. Manual Therapy 13:155-158.

Dreyfuss P, Dreyer S J, Cole A, Mayo K 2004 Sacroiliac Joint Pain. Journal of the American Academy of Orthopaedic Surgeons 12(4):255265.
Foley BS, Buschbacher R M 2007 Sacroiliac Joint Pain: Anatomy, Biomechanics, Diagnosis, and Treatment. American Journal of Physical Medicine Rehabilitation 86(12):1032-1033.

Fryer G, Morse CM, Johnson J C 2009 Spinal and Sacroiliac Assessment And Treatment Techniques Used By Osteopathic Physicians In The US. Oestopathic Medicine and Primary Care 3:4-10.

Forst SL, Wheeler M T, Fortin JD, Vilensky JA 2006 The Sacroiliac Joint: Anatomy, Physiology and Clinical Significance. Pain Physician 9:61-68.

Franke BA 2003 Formative Dynamics: The Pelvic Girdle. The Journal of Manual And Manipulative Therapy 11(1): 12-40

Hansen H C, Mckenzie-Brown AM, Cohen SP, Swicegood JR, Colson JD, Manchikanti L 2007 Sacroiliac Joint Intervention: A Systematic Review. Pain Physician 10(1):165-184.

Hancock MJ, Maher CG, Latimer J, Spindler MF, Mcauley JH, Laslett M, Bogduk N 2007 Systematic Review Of Tests To Identify The Disc, SIJ Or Facet Joint As The Source Of Low Back Pain. European Spine Journal 16:1539-1550.

Harman K, Fenety A, Hoens A, Crouse J, Padfield B 2009 Physiotherapy and low back pain in the injured worker: an examination of current practice during the subacute phase of healing. Physiotherapy Canada 61:88-106.

Horton SJ, Franz A 2007 Mechanical Diagnosis And Therapy Approach To Assessment And Treatment Of Derangement Of The Sacroiliac Joint. Manual Therapy 12: 126-132.

Hungerford B, Gilleard W, Hodges P 2003 Evidence of Altered Lumbopelvic Muscle Recruitment In The Presence Of Sacroiliac Joint Pain. Spine 28(14): 1593-1600.

Laslett M 2008 Evidence-Based Diagnosis and Treatment of the Painful Sacroiliac Joint: A Clinical Perspective. The Journal of Manual and Manipulative Therapy 16(3): 142-152.

Liebenson C 2004 The Relationship Of The Sacroiliac Joint, Stabilization Musculature, And Lumbopelvic Instability. Journal Of Bodywork And Movement Therapies 8: 43-45

Lewit K, Rosina A 1999 Why Yet Another Diagnostic Sign Of Sacroiliac Movement Restriction. Journal of Manipulative and Physiological Therapeutics 22(3): 154-160.

Lurie JD 2005 What Diagnostic Tests Are Useful For Low Back Pain? Best Practice \& Research Clinical Rheumatology 19(4): 557-575.

Mitchell DA, Esler DM 2009 Pelvic Instability - Painful Pelvic Girdle In Pregnancy. Australian Family Physician 38(6): 409-410.
O’Sullivan P, Beales, DJ 2007 Diagnosis and classification pf pelvic girdle pain disordersPart 1: A mechanism based approach within a biopsychosocial framework. Manual Therapy 12: 86-97.

O'Sullivan P 2004 Clinical Instability of the Lumbar Spine, Modern Manual Therapy. Boyling and Jull. $3^{\text {rd }}$ Ed. Elsevier : Amsterdam.

Poitras S, Blais R, Swaine B, Rossignol M 2005 Management of work-related low back pain: a population-based survey of physical therapists. Physical Therapy 85:1168-81

Richardson, C. A., Snijders, C. J., Hides, J., Damen, L., Martijn, S. \& Storm, J. The Relation between Transverse Abdominis Muscles, Sacroiliac Joint Mechanics, and Low Back Pain. Spine 2002; 27(4): 399-405.

Rupert MP, Lee M, Manchikanti L, Datta S, Cohen SP 2009 Evaluation Of Sacroiliac Joint Interventions: A Systematic Appraisal Of The Literature. Pain Physician 12:399-418.

Schwarzer AC, Aprill CN, Bogduk N 1995 The sacroiliac joint in chronic low-back-pain. Spine 20:31-37.

Szadek KM, Van Der Wurff P, Van Tulder MW, Zuurmond WW, Perez RR 2008 Diagnostic validity of criteria for sacroiliac joint pain: a systematic review. Journal of Pain 10(4): 354-368.

Sizer PS, Phelps V, Thompsen K 2002 Disorders of the Sacroiliac Joint. World Institute Of Pain 2(1):17-34

Snijdersad CJ, Ribbersa M, De Bakker H, Stoeckertb R Stamc HJ 1998 EMG Recordings Of Abdominal And Back Muscles In Various Standing Postures: Validation Of A Biomechanical Model On Sacroiliac Joint Stability. Electromyography and Kinesiology 8(4): 205-214.

Toussaint R, Gawlik CS, Rehder U, Ruther W 1999 Sacroiliac Dysfunction In Construction Workers. Journal Manipulative Physiptherapy 22(3): 134-138.

Vanelderen P, Szadek K, Cohen SP, De Witte J, Lataster A, Patijin J, Mekhail N, Van Kleef M, Van Zundert, J 2010 Sacroilliac Joint Pain, Pain Practice 10(5):470-478.

Van Wingerden JP, Vleeming A, Buyruk HM, Raissadat K 2004 Stabilisation of the Sacroiliac Joint in Vivo: Verification of Muscular Contribution To Force Closure Of The Pelvis. European Spine Journal 13(3): 199-205.

Vleeming A, Albert HB, Ostgaard HC, Sturessson B, Stuge B 2008 European Guidelines For The Diagnosis And Treatment Of Pelvic Girdle Pain. European Spine Journal 17: 794-819. 